\title{
PENERAPAN MODEL PEMBELAJARAN KOOPERATIF TIPE THINK PAIR SHARE (TPS) UNTUK MENINGKATKAN AKTIVITAS DAN HASIL BELAJAR PASSING BOLA BASKET
}

\author{
Dian Anggraini' ${ }^{1}$ I Gusti Lanang Agung Parwata², Ni Putu Dwi Sucita Dartini ${ }^{3}$ \\ 1,2,3 Program Studi Penjaskesrek, Universitas Pendidikan Ganesha \\ Singaraja-Indonesia \\ e-mail : dian_anastasius@yahoo.com, agung.parwata@undiksha.ac.id \\ $\underline{\text { sucita.dartini@undiksha.ac.id }}$
}

\begin{abstract}
Abstrak
Penelitian ini bertujuan untuk meningkatkan aktivitas dan hasil belajar passing bola basket pada peserta didik kelas XI IPS 5 SMA Negeri 1 Asembagus tahun pelajaran 2019/2020. Penelitian ini merupakan penelitian tindakan kelas, yaitu guru sebagai peneliti. Penelitian tindakan kelas ini dilaksanakan dalam dua siklus. Terdiri dari rencana tindakan, pelaksanaan tindakan, observasi dan refleksi. Subjek penelitian yaitu peserta didik kelas XI IPS 5 SMA Negeri 1 Asembagus tahun pelajaran 2019/2020, yang berjumlah 36 peserta didik dengan rincian 15 peserta didik putri dan 21 peserta didik putra. Data dianalisis menggunakan analisis statistik deskriptif. Hasil analisis data rata-rata aktivitas belajar secara klasikal teknik dasar passing bola basket pada siklus I sebesar 7,1 (aktif), dan meningkat menjadi 8,4 (aktif) pada siklus II. Sedangkan presentase ketuntasan hasil belajar secara klasikal pada siklus I sebesar 86,1\% (baik), dan meningkat menjadi 100\% (sangat baik) pada siklus II. Berdasarkan hasil analisis data dapat disimpulkan bahwa aktivitas dan hasil belajar passing bola basket (chest pass dan bounce pass) meningkat melalui penerapan model pembelajaran kooperatif tipe TPS pada peserta didik kelas kelas XI IPS 5 SMA Negeri 1 Asembagus tahun pelajaran $2019 / 2020$.
\end{abstract}

Kata-kata kunci: Think Phare Share, aktivitas belajar, hasil belajar, passing bola basket

\begin{abstract}
This study aims to improve the activity and learning outcomes basic ball techniques for students in class XI IPS 5 Asembagus State High School 1 Academic Year 2019-2020. This research is a classroom action research, which is the teacher as a researcher. This classroom action research was carried out in two cycles. Consisting of action plans, action implementation, observation and reflection. The research subjects are students of class XI IPS 5 SMA 1 Asembagus in Academic Year 2019/2020, totaling 36 students with details of 15 female students and 21 male students. Data were analyzed using descriptive analysis. The results of data analysis on average learning activities in classical were 7.1 (active), and increased to 8.4 (active) in cycle II. While the percentage of completeness of classical learning outcomes in cycle I was $86.1 \%$ (good), and increased to $100 \%$ (very good) in cycle II.
\end{abstract}


It can be concluded that the activity and learning outcomes of basketball passing (chest pass and bounce pass) increased through the application of TPS type cooperative learning models for students in class XI IPS 5 in SMA Negeri 1 Asembagus in 2019/2020 school year.

Keywords: Think Phare Share, learning activities, learning outcomes, basketball passes

\section{PENDAHULUAN}

Pembelajaran merupakan suatu proses yang melibatkan interaksi antara peserta didik dengan guru maupun peserta didik dengan peserta didik dimana dari interaksi tersebut peserta didik diharapkan mendapatkan pemahaman dan kemajuan hasil belajar tentang ajaran yang diperoleh dalam situasi pembelajaran. Dalam pelaksanaan pembelajaran tersebut selalu terkait dengan beberapa faktor, salah satunya adalah faktor internal peserta didik yang bersangkutan. Faktor internal peserta didik adalah faktor yang timbul dari dalam peserta didik, seperti peserta didik kurang tertarik terhadap materi pembelajaran yang diberikan.

$$
\text { Pembelajaran Pendidikan }
$$

Jasmani Olahraga dan Kesehatan (PJOK)pada khususnya masih mengalami permasalahan karena model pembelajaran yang digunakan masih kurang maksimal. Hal tersebut dapat dilihat melalui observasi yang dilakukan, dimana proses pembelajaran masih berpusat pada guru. Guru belum memaksimalkan fungsi kelompok dalam pembelajaran, selama ini pembentukan kelompok hanya sebatas mempermudah melakukan presensi, dan peserta didik masih terlihat canggung untuk menyampaikan kesulitankesulitan dalam melakukan tugas gerak. Dengan model pembelajaran tersebut, peserta didik cepat merasa bosan dalam mengikuti proses pembelajaran dan beberapa peserta didik menganggap PJOK adalah mata pelajaran yang menakutkan karena memerlukan kesiapan fisik untuk melakukan tugas gerak. Selain itu terlihat terdapat peserta didik yang mengalami kesulitan tugas gerak namun tidak berani bertanya, selain itu terdapat juga peserta didik yang tidak berani mencoba dengan alasan takut cedera. Sehingga beberapa peserta didik yang sudah menguasai tugas gerak dengan baik mendominasi aktivitas pembelajaran tanpa berbagi dengan temannya yang mengalami kesulitan.

Berdasarkan observasi awal yang dilakukan pada tanggal 15 Juli 2019 di SMA 1 Asembagus, Situbondo pada peserta didik kelas XI IPS 5 dalam mata pelajaran penjaskes khususnya pada materi passing bola basket (chest pass dan bounce pass) dengan jumlah peserta didik sebanyak 36 orang. Dilihat dari aktivitas belajar, didapatkan ratarata aktivitas belajar peserta didik secara klasikal adalah 5,6. Adapun yang tergolong aktif sebanyak 4 orang $(11,1 \%)$, yang tergolong cukup aktif sebanyak 27 orang (75\%), yang tergolong kurang aktif sebanyak 5 orang $(13,9 \%)$, dan yang tergolong sangat kurang aktif tidak ada. Hasil tersebut dilihat dari aktivitas belajar peserta didik di lapangan yang meliputi kegiatan visual, audio, lisan, metrik, mental serta emosional. Dari hasil tersebut, maka dapat dikatakan aktivitas belajar peserta didik secara klasikal pada mata pelajaran penjaskes khususnya materi teknik passing bola basket adalah cukup aktif. Namun penulis berpendapat hal itu dapat ditingkatkan lagi serta perlu adanya 
perbaikan dalam penggunaan model pembelajaran sehingga sesuai dengan kondisi peserta didik terkini serta dapat meningkatkan aktivitas belajar peserta didik.

Dilihat dari hasil belajar peserta didik pada materi teknik passing bola basket peserta didik yang mendapatkan nilai dengan kategori sangat baik tidak ada, peserta didik dalam kategori baik sebanyak 8 orang $(22,2 \%)$, peserta didik dalam kategori cukup baik sebanyak 21 orang $(58,3 \%)$, peserta didik dalam kategori kurang baik sebanyak 7 orang $(19,5 \%)$, dan peserta didik dalam kategori sangat kurang baik tidak ada. Peserta didik yang tuntas sebanyak 8 orang atau 22,2\% dan peserta didik yang tidak tuntas sebanyak 28 orang atau $77,8 \%$, dan dengan rata-rata hasil belajar secara klasikal 65,80\%.

Berdasarkan hasil observasi awal yang telah dilakukan, banyak permasalahan yang menyebabkan aktivitas dan hasil belajar pada peserta didik masih berada dalam kategori cukup aktif, yaitu kurangnya penerapan model pembelajaran yang lebih banyak melibatkan interaksi di antara peserta didik, dan keterbatasan waktu dalam proses belajar mengajar, dilihat juga dari aspek aktivitas belajar ditemukan masih kurangnya peserta didik dalam memperhatikan (visual) serta mendengarkan (audio), dan semangat (emosional) peserta didik dalam proses pembelajaran yang masih kurang.Bertolak dari uraian di atas maka peneliti mencoba memberikan alternative pemecahan masalah untuk pembelajaran selanjutnya pada materi passing bola basket yaitu dengan menggunakan model pembelajaran kooperatif tipe Think Pair Share (TPS). Karena model pembelajaran kooperatif tipe Think Pair Share (TPS) menuntut para peserta didik untuk memiliki kemampuan yang baik dalam berkomunikasi maupun dalam keterampilan proses kelompok. "Model ini adalah cara yang efektif untuk membuat variasi suasana pola diskusi kelas, dan memberikan banyak waktu peserta didik berpikir, untuk merespon dan saling membantu satu sama lain atau pasangannya" (Trianto, 2007:61). Sejalan dengan itu, menurut Hatina, 2008 mengemukakan bahwa TPS merupakan suatu model pembelajaran kooperatif sederhana yang memiliki prosedur secara eksplisit sehingga model pembelajaran TPS dapat disosialisasikan dan digunakan sebagai alternatif dalam pembelajaran di sekolah. Sedangkan menurut Arends (dalam Komalasari,2011: 64) menyatakan bahwa TPS merupakan suatu cara yang efektif untk membuat variasi suasana pola diskusi kelas.

Penerapan model pembelajaran tipe TPS akan membuat peserta didik, (1) lebih aktif untuk menemukan konsep PJOK, mengembangkan sendiri fakta, teori, dan prinsip yang ditemukan, serta memecahkan masalah yang ditemukan berdasarkan konsep yang ada, sehingga peserta didik terhindar dari belajar menghafal, (2) lebih kreatif dan komperhensif untuk menyampaikan gagasan, bertanya dan menanggapi setiap permasalahan yang disampaikan, (3) memudahkan peserta didik melakukan penyesuaian social dan secara tidak langsung belajar dasardasar berorganisasi, (4) menghilangkan sifat mementingkan diri sendiri atau egois dan egosentris, (5) membangun persahabatan yang dapat berlanjut hingga masa dewasa, (6) merubah pandangan peserta didik terhadap guru, bahwa guru sebagai fasilitator bukan sebagai penunjang keberhasilan akademik. Dari penerapan model pembelajaran kooperatif tipe TPS tersebut, diharapkan nantinya mampu memotivasi peserta didik untuk belajar 
dengan baik dan merubah pandangan mereka terhadap mata pelajaran PJOK dari pelajaran yang membosankan menjadi pelajaran yang menarik, tetapi juga berdampak pada peningkatan kompetensi dasar peserta didik. Pemilihan tentang model pembelajaran TPS ini juga dikuatkan oleh hasil penelitian dari penelitipeneliti sebelumnya, diantaranya: 1) I Gusti Lanang Agung Parwata (2014) menyatakan bahwa aktivitas dan hasil belajar gerak dasar lompat jauh meningkat melalui implementasi model pembelajaran kooperatif tipe TPS pada siswa kelas V MIN Singaraja Tahun Pelajaran 2013 / 2014, 2) I Komang Wiwik Sandita (2012) menemukan bahwa aktivitas dan hasil belajar teknik dasar passing bola sepak meningkat melalui penerapan model pembelajaran kooperatif tipe TPS pada peserta didik kelas X 1 SMA Negeri 1 Blahbatuh tahun pelajaran 2011/2012, 3) I Gede Putrawan (2013) menemukan bahwa aktivitas dan hasil belajar teknik passing bola voli meningkat melalui penerapan model pembelajaran kooperatif tipe TPS pada peserta didik kelas VIII 1 SMP Negeri 4 Kuta Selatan tahun pelajaran 2012/2013, 4) I Kade Supardika (2013) menemukan bahwa aktivitas dan hasil belajar teknik dasar berguling senam lantai meningkat melalui penerapan model pembelajaran kooperatif tipe tipe TPS pada peserta didik kelas VII A SMP Negeri 4 Negara tahun pelajaran 2012/2013, 5) Charly Charles Johnry Koloay (2017) menemukan bahwa aktivitas dan hasil belajar passingbola voli (passing bawah dan passing atas) meningkat melalui penerapan model pembelajaran kooperatif tipe TPS pada peserta didik kelas XI MIPA 4 SMA Negeri 2 Singaraja tahun pelajaran 2017/2018, 6) Komang Budi Satriawan (2017) menemukan bahwa aktivitas dan hasil belajar keterampilan gerak passing permainan sepakbola menggunakan kaki bagian dalam meningkat melalui implementasi model pembelajaran kooperatif tipe TPS pada peserta didik kelas XI UPW B SMK Negeri 1 Singaraja tahun pelajaran 2017/2018.

Berdasarkan uraian di atas peneliti merasa terdorong untuk melakukan penelitian yang berjudul "Penerapan Model Pembelajaran Kooperatif tipe Think Pair Share (TPS) Untuk MeningkatkanAktivitas dan Hasil Belajar PassingBola Basket Pada Peserta Didik Kelas XI IPS5 SMA Negeri 1 Asembagus Tahun Pelajaran 2019/2020".

\section{METODE}

Jenis penelitian yang digunakan dalam penelitian ini adalah penelitian tindakan kelas (PTK) classroom action research. "Penelitian tindakan kelas adalah suatu bentuk penelitian yang bersifat reflektif dengan melakukan tindakan-tindakan tertentu agar dapat memperbaiki atau meningkatkan praktek-praktek pembelajaran di kelas secara lebih professional" (Kanca, 2010:108).

Oja SN (dalam Kanca, I Nyoman, 2010: 115) mengatakan bahwa ada empat bentuk penelitian tindakan kelas (PTK) yaitu: (1) Guru sebagai peneliti, (2) Penelitian tindakan kolaboratif, (3) Simultan terintegrasi. (4) Administrasi sosial eksperimental. Dalam penelitian ini bentuk penelitian tindakan yang digunakan adalah guru sebagai peneliti.

Penelitian tindakan kelas ini dilaksanakan di kelas XI IPS 5 SMA Negeri 1 Asembagus Tahun Pelajaran 2019/2020. Dilaksanakan sebanyak dua siklus dengan masing-masing siklus terdiri dari 2 (dua) kali pertemuan. Pertemuan pertama dengan pemberian tindakan dan pengamatan aktivitas 
belajar peserta didik, satu pertemuan lagi untuk pengamatan aktivitas belajar dan evaluasi hasil belajar. Masingmasing siklus terdiri dari empat tahapan, yaitu: 1) rencana tindakan ,2) pelaksanaan tindakan, 3) observasi dan evaluasi, 4) refleksi. Dalam penelitian ini, peneliti menggunakan analisis statistik deskriptif. Adapun langkahlangkahnya adalah sebagai berikut:

1. Analisis Aktivitas Belajar Teknik Dasar Passing Bola Basket

a. Analisis Aktivitas Belajar Peserta didik

Data aktivitas (berupa skor) peserta didik diamati dan dicatat dalam lembar observasi, selanjutnya dianalisis secara deskriptif. Kriteria yang digunakan dalam menggolongkan aktivitas belajar peserta didik disusun berdasarkan ratarata skor keaktifan belajar peserta didik secara klasikal $(\bar{X})$, mean ideal (Mi), dan standar deviasi ideal (SDi). Rumusan untuk Mi dan SDi adalah $\mathrm{Mi}=\frac{1}{2} \mathrm{x}$ (skor tertinggi ideal + skor terendah ideal)

$\mathrm{SDi}=\frac{1}{3} \mathrm{x} \mathrm{Mi}$

(Nurkancana dan Sunartana, 1990: 100) Keterangan:

Mi : Mean Ideal (angka rata-rata ideal)

SDi : Standar Deviasi Ideal

Tabel 1. Kriteria Penggolongan Aktivitas Belajar Teknik Dasar Passing Bola Basket

\begin{tabular}{ccll}
\hline No & \multicolumn{1}{c}{ Kriteria } & \multicolumn{1}{c}{ Kategori } & Predikat \\
\hline 1 & $\bar{X} \geq \mathrm{Mi}+1,5 \mathrm{Sdi}$ & Sangat Aktif & \multirow{2}{*}{ Aktif } \\
2 & $\mathrm{Mi}+0,5 \mathrm{SDi} \leq \bar{X}<\mathrm{Mi}+1,5 \mathrm{Sdi}$ & Aktif & \\
3 & $\mathrm{Mi}-0,5 \mathrm{SDi} \leq \bar{X}<\mathrm{Mi}+0,5 \mathrm{Sdi}$ & Cukup Aktif & Tidak \\
4 & $\mathrm{Mi}-1,5 \mathrm{SDi} \leq \bar{X}<\mathrm{Mi}-0,5 \mathrm{Sdi}$ & Kurang Aktif & aktif \\
5 & $\bar{X}<\mathrm{Mi}-1,5 \mathrm{Sdi}$ & Sangat Kurang Aktif & \\
\hline
\end{tabular}

Indikator yang digunakan untuk mengobservasi aktivitas belajar peserta didik sebanyak 6 indikator. Dengan demikian perhitungan $\mathrm{Mi}$ dan SDi adalah sebagai berikut.

$$
\begin{aligned}
\mathrm{Mi} & =\frac{1}{2} \times 12 \\
& =6 \\
\mathrm{SDi} & =\frac{1}{3} \times 6 \\
& =2
\end{aligned}
$$

Tabel 2. Pedoman Penggolongan aktivitas Belajar Teknik Dasar Passing Bola Basket

\begin{tabular}{cccc}
\hline No & Kriteria & Kategori & Predikat \\
\hline 1 & $\bar{X} \geq 9$ & Sangat Aktif & \multirow{2}{*}{ Aktif } \\
2 & $7 \leq \bar{X}<9$ & Aktif & \\
3 & $5 \leq \bar{X}<7$ & Cukup Aktif & \\
4 & $3 \leq \bar{X}<5$ & Kurang Aktif & Tidak Aktif \\
5 & $\bar{X}<3$ & Sangat Kurang & \\
& & Aktif & \\
\hline
\end{tabular}


Penelitian tindakan kelas ini bisa dikatakan berhasil apabila aktivitas belajar peserta didik minimal berada pada kategori aktif $(7 \leq \bar{X}<9)$, baik secara individu maupun klasikal.

\section{Analisis Hasil Belajar Peserta Didik}

Nilai $=\frac{\text { Skor Diperoleh }}{\text { Skor Maksimal }} \times 100 \%$

Tabel 3 Konversi Nilai Ketuntasan Mata Pelajaran Passing Bola Basket

\section{Rentang Skor dalam \%}

91-100

$83-90$

$75-82$

$$
<74
$$

Menghitung persentase tingkat ketuntasan hasil belajar secara klasikal menggunakan rumus sebagai berikut:

\section{$K B$ \\ $=\frac{\text { Jumlah siswa tuntas }}{\text { Jumlah siswa seluruhnya }} \times 100 \%$ \\ Keterangan: \\ $\mathrm{KB}=$ Ketuntasan Belajar \\ HASIL DAN PEMBAHASAN \\ Hasil Penelitian \\ a. Siklus I}

Nilai rata-rata aktivitas belajar pada siklus I adalah: 7,1 (kategori Aktif) dengan rincian yaitu sebanyak 32 orang (89\%) berada pada kategori aktif dan 4 orang $(11 \%)$ berada pada kategori cukup aktif. Sedangkan data hasil belajar siklus I secara klasikal yaitu 78,97 (kategori Cukup) dengan rincian sebanyak 8 orang $(22,2 \%)$ dengan kategori Baik, 23 orang $(63,8 \%)$ berada pada kategori Cukup, dan sebanyak 5 orang $(13,8 \%)$ berada pada kategori Kurang. Berdasarkan tingkat ketuntasan, ditemukan sebanyak 31 orang $(86 \%)$ tuntas dan 5 orang $(13,8 \%)$ tidak tuntas.

Berdasarkan data diatas disimpulkan bahwa tingkat ketuntasan belajar pada

$\begin{array}{cc}\text { Kategori } & \text { Keterangan } \\ \text { Sangat Baik } & \text { Tuntas } \\ \text { Baik } & \text { Tuntas } \\ \text { Cukup } & \text { Tuntas } \\ \text { Kurang } & \text { Tidak Tuntas }\end{array}$

siklus I adalah sebesar $86,1 \%$ atau berada pada kategori Baik.

\section{b. Siklus II}

Nilai rata-rata aktivitas belajar pada siklus II adalah: 8,4 (kategori Aktif) dengan rincian yaitu sebanyak 10 orang (28\%) berada pada kategori sangat aktif dan 26 orang $(72,2 \%)$ berada pada kategori aktif. Sedangkan data hasil belajar siklus II secara klasikal yaitu 88,5 (kategori Baik) dengan rincian sebanyak 10 orang (28\%) dengan kategori Sangat Baik, dan sebanyak 26 orang $(72,2 \%)$ berada pada kategori Baik.

Berdasarkan data diatas disimpulkan bahwa tingkat ketuntasan belajar pada siklus II adalah sebesar $100 \%$ atau berada pada kategori Sangat Baik. Peningkatan Aktivitas Belajar Per Siklus Materi Teknik Dasar Passing (chest pass dan bounce pass) pada peserta didik kelas XI IPS 5 SMA Negeri 1 Asembagus tahun pelajaran $2019 / 2020$

Tabel 4. Data Aktivitas Belajar Peserta Didik (Siklus I dan Siklus II) 


\begin{tabular}{|c|c|c|c|c|}
\hline No & Tahapan & $\begin{array}{c}\text { Aktivitas } \\
\text { Belajar Klasikal }\end{array}$ & $\begin{array}{c}\text { Keaktifan } \\
\text { Peserta didik }\end{array}$ & $\begin{array}{c}\text { Peningkatan Siklus I } \\
\text { ke Siklus II }\end{array}$ \\
\hline 1 & Siklus I & 7,1 & $\begin{array}{l}32 \text { peserta didik } \\
(89 \%) \\
\text { Aktif }\end{array}$ & \\
\hline 2 & Siklus II & 8,4 & $\begin{array}{l}36 \text { peserta didik } \\
(100 \%) \\
\text { Aktif }\end{array}$ & $\begin{array}{l}4 \text { peserta didik } \\
(11 \%)\end{array}$ \\
\hline
\end{tabular}

Peningkatan Hasil Belajar Peserta didik Per Siklus Materi Teknik Dasar Passing (chest pass dan bounce pass) Bola
Basket pada Peserta didik Kelas XI IPS 5 SMA Negeri 1 Asembagus tahun pelajaran 2019/2020

Tabel 5. Data Hasil Belajar Passing Peserta Didik (Siklus I dan Siklus II)

\begin{tabular}{|c|c|c|c|c|}
\hline No & Tahapan & \begin{tabular}{|l} 
Persentase \\
Hasil Belajar
\end{tabular} & $\begin{array}{c}\text { Ketuntasan } \\
\text { Peserta didik }\end{array}$ & $\begin{array}{c}\text { Peningkatan Siklus } \\
\text { I ke Siklus II }\end{array}$ \\
\hline 1 & Siklus I & $\begin{array}{l}31 \text { peserta didik } \\
(86 \%) \text { tuntas }\end{array}$ & Tuntas & \\
\hline 2 & Siklus II & $\begin{array}{c}36 \text { peserta didik } \\
(100 \%) \\
\text { tuntas }\end{array}$ & Tuntas & 5 peserta didik $(14 \%)$ \\
\hline
\end{tabular}

\section{PEMBAHASAN}

Berdasarkan hasil penelitian yang telah dilakukan selama dua siklus, menunjukkan terjadi peningkatan aktivitas dan hasil belajar peserta didik dengan penerapan model pembelajaran kooperatif tipe TPS. Adapun data yang diperoleh berdasarkan analisis data pada siklus I yaitu rata-rata aktivitas belajar peserta didik dalam proses pembelajaran secara klasikal sebesar 7,1. Dari kriteria $7 \leq \bar{X}<9$ pada siklus I tergolong aktif. Sedangkan persentase hasil belajar secara klasikal sebesar 78,97 dalam predikat cukup baik.

Pada pembelajaran siklus I banyak peserta didik yang masih malumalu dalam mengemukakan pendapat, peserta didik masih tidak percaya diri dalam mendemonstrasikan gerakan passing kepada teman-temannya, ada pula beberapa peserta didik putri yang enggan satu kelompok dengan peserta didik putra.

Namun, Pembelajaran pada siklus II berlangsung dengan kondusif, peserta didik sudah mampu beradaptasi dengan model pembelajaran kooperatif tipe TPS. Hal ini terlihat dari aktivitas belajar peserta didik saat peneliti memperagakan gerakan, peserta didik tidak lagi hanya menonton tetapi ikut aktif dalam memberikan komentar terhadap penjelasan peneliti di setiap tahap gerakan yang diperagakan oleh peneliti maupun teman kelompoknya, sebagian besar peserta didik sudah bagus dalam mempraktikkan gerakan passing, hampir seluruh peserta didik 
sudah aktif dalam pembelajaran berkelompok, dan peserta didik mampu saling mengkoreksi gerakan passing teman satu sama lain.

Dilihat dari data aktivitas belajar peserta didik teknik dasar passing (chest pass dan bounce pass) bola basket pada siklus II secara klasikal sebesar 8,4. Dari kriteria $7 \leq \bar{X}<9$, maka aktivitas belajar peserta didik pada siklus II tergolong aktif. Sedangkan persentase hasil belajar peserta didik teknik dasar passing (chest pass dan bounce pass) bola basket pada siklus II sebesar 88,5 yang tergolong dalam kategori baik.

Dari data tersebut terlihat adanya peningkatan dari siklus I ke siklus II. Peningkatan Aktivitas belajar sebesar $11 \%$ dan peningkatan Hasil belajar sebesar sebesar $14 \%$. Peningkatan ini tidak terlepas dari penerapan model pembelajaran kooperatif tipe Think Pair Share (TPS) karena model pembelajaran TPS dapat memberikan lebih banyak kesempatan kepada peserta didik untuk berpikir sendiri dan mencari jawaban sendiri sehingga hal tersebut membuat peserta didik lebih aktif dan antusias dalam proses pembelajaran. Menurut Arends (dalam Trianto 2007: 61) mengemukakan bahwa think pair share merupakan suatu cara yang efektif untuk membuat variasi suasana pola diskusi kelas, dengan asumsi bahwa semua resitasi atau diskusi membutuhkan pengaturan untuk mengendalikan kelas secara keseluruhan, dan prosedur yang digunakan dalam think pair share dapat memberi siswa lebih banyak waktu berpikir, untuk merespon dan saling membantu. Hamalik (2008: 171-172) menyatakan bahwa "pembelajaran yang efektif adalah pembelajaran yang menyediakan kesempatan belajar sendiri dan beraktivitas sendiri kepada peserta didik". Peserta didik belajar dan beraktivitas sendiri untuk memperoleh pengalaman, pengetahuan, pemahaman, dan tingkah laku lainnya serta mengembangkan keterampilan yang bermakna.Sehingga dapat disimpulkan bahwa kegiatan atau aktivitas belajar peserta didik merupakan dasar untuk mencapai hasil belajar yang optimal.

Selain itu hasil penelitian ini juga didukung dan dikuatkan oleh peneliti-peneliti lainnya, diantaranya: : 1) I Gusti Lanang Agung Parwata (2014) menyatakan bahwa aktivitas dan hasil belajar gerak dasar lompat jauh meningkat melalui implementasi model pembelajaran kooperatif tipe TPS pada siswa kelas V MIN Singaraja Tahun Pelajaran 2013 / 2014, 2) I Komang Wiwik Sandita (2012) menemukan bahwa aktivitas dan hasil belajar teknik dasar passing bola sepak meningkat melalui penerapan model pembelajaran kooperatif tipe TPS pada peserta didik kelas X 1 SMA Negeri 1 Blahbatuh tahun pelajaran 2011/2012, 3) I Gede Putrawan (2013) menemukan bahwa aktivitas dan hasil belajar teknik passing bola voli meningkat melalui penerapan model pembelajaran kooperatif tipe TPS pada peserta didik kelas VIII 1 SMP Negeri 4 Kuta Selatan tahun pelajaran 2012/2013, 4) I Kade Supardika (2013) menemukan bahwa aktivitas dan hasil belajar teknik dasar berguling senam lantai meningkat melalui penerapan model pembelajaran kooperatif tipe tipe TPS pada peserta didik kelas VII A SMP Negeri 4 Negara tahun pelajaran 2012/2013, 5) Charly Charles Johnry Koloay (2017) menemukan bahwa aktivitas dan hasil belajar passingbola voli (passing bawah dan passing atas) meningkat melalui penerapan model pembelajaran kooperatif tipe TPS pada peserta didik kelas XI MIPA 4 SMA Negeri 2 Singaraja tahun pelajaran 2017/2018,6) Komang Budi Satriawan (2017) 
menemukan bahwa aktivitas dan hasil belajar keterampilan gerak passing permainan sepakbola menggunakan kaki bagian dalam meningkat melalui implementasi model pembelajaran kooperatif tipe TPS pada peserta didik kelas XI UPW B SMK Negeri 1 Singaraja tahun pelajaran 2017/2018.

\section{PENUTUP}

\section{Simpulan}

Berdasarkan hasil analisis data dan pembahasan, dapat disimpulkan hahal sebagai berikut.

Melalui penerapan model pembelajaran kooperatif tipe TPS pada mata pelajaran penjasorkes materi passing (chest pass dan bounce pass) di kelas XI IPS 5 dapat meningkatkan aktivitas belajar peserta didik. Hal ini sesuai dengan pengamatan yang peneliti lakukan menunjukkan bahwa adanya peningkatan dari siklus I sebesar 7,1 menjadi 8,4 pada siklus II.

Melalui penerapan model pembelajaran kooperatif tipe TPS pada mata pelajaran penjasorkes materi passing (chest pass dan bounce pass ) di kelas XI IPS 5 dapat meningkatkan hasil belajar peserta didik. Hal ini sesuai dengan pengamatan yang peneliti lakukan menunjukkan bahwa adanya peningkatan hasil belajar dari siklus I sebesar 78,97 menjadi 88,5 pada siklus II.

\section{Saran}

Saran yang dapat diajukan berdasarkan hasil penelitian yang telah dilakukan adalah: (1) kepada peserta didik yang dijadikan subyek penelitian selanjutnya lebih memperhatikan dan memahami pembelajaran yang diberikan, agar dapat menambah paradigma maupun wawasan pengetahuan khususunya dalam pembelajaran teknik dasar passing bola basket maupun pada pembelajaran yang lain. (2) kepada guru penjasorkes agar mengimplementasikan model pembelajaran kooperatif tipe TPS, karena terbukti dapat meningkatkan aktivitas dan hasil belajar peserta didik teknik dasar passing bola basket. (3) kepada peneliti lain yang akan mengadakan penelitian dapat menerapkan model pembelajaran kooperatif tipe TPS.

\section{DAFTAR RUJUKAN}

Hamalik, O. 2001. Proses Belajar Mengajar. Jakarta: PT Bumi Aksara.

Kanca, I.N. 2010. Metode Penelitian Pengajaran Pendidikan Jasmani. Singaraja: Universitas Pendidikan Ganesha.

Koloay, C.C.J. (2017). IMPLEMENTASI MODEL KOOPERATIF TPS MENINGKATKAN AKTIVITAS HASIL BELAJAR PASSING BOLA VOLI. Jurnal Penelitian dan Pengembangan Pendidikan, Vol. 1 No. 3 (hlm. 98-109).

Nurkancana dan Sunartana. 1990. Evaluasi Hasil Belajar. Surabaya: Usaha Nasional.

Parwata, I. G. L. A. (2014). IMPLEMENTASI MODEL PEMBELAJARAN

KOOPERATIF TIPE THING PAIR SHARE (TPS) UNTUK MENINGKATKAN AKTIVITAS DAN HASIL BELAJAR GERAK DASAR LOMPAT JAUH SISWA KELAS V MIN SINGARAJA TAHUN AJARAN 2013/2014. Jurnal Pendidikan Jasmani, 
Olahraga dan Kesehatan Undiksha, 2(1).

Putrawan, I.G. (2013).PENERAPAN KOOPERATIF TPS UNTUK MENINGKATKAN

AKTIVITAS DAN HASIL BELAJAR PASSING BOLA VOLI SISWA KELAS VIII 1 SMP NEGERI 4 KUTA SELATAN TAHUN PELAJARAN 2012/2013. Jurnal Pendidikan Jasmani, Olahraga dan Kesehatan. Vol. 1 No. 3.

Satriawan,

K.B.

(2017).

IMPLEMENTASI MODEL PEMBELAJARAN

KOOPERATIF TPS UNTUK MENINGKATKAN

AKTIVITAS DAN HASIL BELAJAR PASSING SEPAKBOLA. Jurnal Penelitian dan Pengembangan Pendidikan. Vol. 1 No. 2 (hlm.40-48).
Sudjana, Nana. 2004. Penilaian Hasil Proses Belajar Mengajar. Bandung: PT Remaja Rosdakarya.

Supardika, I.K. (2013). PENERAPAN KOOPERATIF TPS MENINGKATKAN

AKTIVITAS DAN HASIL BELAJAR ROLL SENAM LANTAI SISWA KELAS VII.A SMP NEGERI 4 NEGARA TAHUN PELAJARAN 2012/2013. Jurnal Pendidikan Jasmani, Olaharaga dan Kesehatan. Vol. 1 No. 3.

Suprijno, Agus. 2009. Cooperative Learning Teori dan Aplikasi PAIKEM. Yogyakarta: Pustaka Pelajar.

Trianto. 2007. Model-model Pembelajaran Inovatif Berorientasi Konstruktivistik. Jakarta: Perpustakaan Nasional. 